\title{
Correction to: thermal conductivity of porous sintered metal powder and the Langmuir shape factor
}

\author{
Osama M. Ibrahim ${ }^{1}$ (D) $\cdot$ Ahmed H. Al-Saiafi $^{2} \cdot$ Sorour Alotaibi $^{1}$ (D)
}

Published online: 16 April 2021

(C) Springer-Verlag GmbH Germany, part of Springer Nature 2021

\section{Correction to: Heat and Mass Transfer https://doi.org/10.1007/s00231-021-03032-x}

1) On the first page, in the Nomenclatures section, the overbar symbol is missing. Add ${ }^{-}$.

\section{Overbar}

- normalized

2) On Page 3, at the beginning of the second column, correct $\dot{q}, \dot{q}_{s}^{p}$, and $\dot{q}_{f}^{p}$ in the text and Eq. 1; the dots, subscripts, and $\underline{\text { superscripts are misaligned. }}$

At steady state, the total heat flow $(\dot{q})$ in a parallel configuration is the sum of the heat flow in the solid-phase $\left(\dot{q}_{s}^{p}\right)$ plus the heat flow in the fluid-phase $\left(\dot{q}_{f}^{p}\right)$,

$\dot{q}=\dot{q}_{s}^{p}+\dot{q}_{f}^{p}$

3) On Page 4, at the beginning of the second column, correct $\dot{q}, \dot{q}_{s}^{s}$, and $\dot{q}_{f}^{s}$ in the text and Eq. 8; the dots, subscripts, and superscripts are misaligned.

The online version of the original article can be found at https://oi.org/ $10.1007 / \mathrm{s} 00231-021-03032-\mathrm{x}$

Osama M. Ibrahim osama.ibrahim@ku.edu.kw

\section{Ahmed H. Al-Saiafi}

Asaiafi@kockw.com

Sorour Alotaibi

sr.alotaibi@ku.edu.kw

1 Department of Mechanical Engineering, College of Engineering and Petroleum, Kuwait University, P. O. Box 5969, 13060 Safat, Kuwait

2 Kuwait Oil Company (K.S.C.), P.O. Box 9758, 61008 Ahmadi, Kuwait

At steady state, the total heat flow $(\dot{q})$ in a series configuration is equal to the heat flow in the solid-phase $\left(\dot{q}_{s}^{s}\right)$ and the heat flow in the fluid-phase $\left(\dot{q}_{f}^{s}\right)$ :

$\dot{q}=\dot{q}_{s}^{s}=\dot{q}_{f}^{s}$

4) On Page 5, the second column starting with the sentence before Eq. 19a, change Eq. 20 to Eq. 17. Correct, Eqs. 19a and $19 \mathrm{~b}$ by adding overbars, on $\bar{S}_{s}^{p}, \overline{\bar{A}}_{s}^{p}, \bar{S}_{f}^{p}$, and $\bar{A}_{f}^{p}$.

The normalized Langmuir shape factors in Eq. 17 are related to the normalized cross-sectional areas and porosity as follows:

$$
\begin{aligned}
& \vec{S}_{s}^{p}=\frac{S_{s}^{p}}{S}=\frac{\left(A_{s}^{p} / L_{s}^{p}\right)}{(A / L)}=\frac{\left(A_{s}^{p 2} / A^{2}\right)}{\left(L_{s}^{p} A_{s}^{p} / L A\right)}=\frac{\left(\bar{A}_{s}^{p 2}\right)}{(1-P)} \\
& \vec{S}_{f}^{p}=\frac{S_{f}^{p}}{S}=\frac{\left(A_{f}^{p} / L_{f}^{p}\right)}{(A / L)}=\frac{\left(A_{f}^{p 2} / A^{2}\right)}{\left(L_{f}^{p} A_{f}^{p} / L A\right)}=\frac{\left(\bar{A}_{f}{ }^{2}\right)}{P}
\end{aligned}
$$

5) On Page 6, Correct Eqs. 29a and 29b by adding overbars on $\bar{S}_{s}^{s}, \bar{A}^{s}, \bar{S}_{f}^{s}$, and $\bar{A}^{s}$.

$\bar{S}_{s}^{s}=\frac{S_{s}^{s}}{S}=\frac{\left(A^{s} / A\right)}{\left(L_{s}^{s} / L\right)}=\frac{\left(A^{s 2} / A^{2}\right)}{\left(L_{s}^{s} A^{s} / L A\right)}=\frac{\bar{A}^{s 2}}{(1-P)}$
$\bar{S}_{f}^{s}=\frac{S_{f}^{s}}{S}=\frac{\left(A^{s} / A\right)}{\left(L_{f}^{s} / L\right)}=\frac{\left(A^{s 2} / A^{2}\right)}{\left(L_{f}^{s} A^{s} / L A\right)}=\frac{\bar{A}^{s 2}}{P}$

6) On Page 7, the second paragraph on the second column, correct $\dot{q}, \dot{q}_{s}^{p}, \dot{q}_{f}^{p}$, and $\dot{q}_{s f}^{s}$ in the text and Eq. 35; the dots, subscripts, and superscripts are misaligned. 
Assuming the solid and fluid phases of the porous medium are transferring heat in parallel and series at the same time. Simple superpositioning of the parallel and series heat transfer configuration results in an energy balance where the total heat flow $(\dot{q})$, at steady state is the sum of the parallel heat flow in the solid-phase $\left(\dot{q}_{s}^{p}\right)$, the parallel heat flow in the fluidphase $\left(\dot{q}_{f}^{p}\right)$, and the series heat flow through the solid-phase and fluid-phase $\left(\dot{q}_{s f}^{s}\right)$.

$\dot{q}=\dot{q}_{s}^{p}+\dot{q}_{f}^{p}+\dot{q}_{s f}^{s}$

7) On Page 7 , Eq. 36, correct $\bar{k}_{e}, \bar{k}_{f}, \bar{S}_{s}^{p}, \bar{S}_{s}^{s}$, and $\bar{S}_{f}^{s}$ by adding the overbars,

$\bar{k}_{e}=\bar{S}_{s}^{p}+\bar{k}_{f} \bar{S}_{f}^{p}+\frac{\bar{k}_{f} \bar{S}_{s}^{s} \bar{S}_{f}^{s}}{\left(\bar{S}_{s}^{s}+\bar{k}_{f} \bar{S}_{f}^{s}\right)}$

8) On Page 8 , Eq. 41 , correct, $\bar{k}_{e}$ and $\bar{k}_{f}$, by adding the overbars,

$\bar{k}_{e}=(1-P)^{2 n-1}+\frac{\bar{k}_{f}\left(1-(1-P)^{n}\right)^{2}}{P}+\frac{\bar{k}_{f}\left(a P^{m}(1-P)\right)^{2}}{P+\bar{k}_{f}(1-P)}$

9) On Page 8, the beginning of the second column, the last sentence before Section 4, change "Equations 40 to 43 " to "Equations 38 to $41 "$,

Equations. 38 to 41 represent the re-examined parallel-series model.
10) On Page 12, Fig. 13 caption, correct $\left(\dot{q}_{s}^{p} / \dot{q}\right),\left(\dot{q}_{f}^{p} / \dot{q}\right)$, and $\left(\dot{q}_{s f}^{p} / \dot{q}\right)$; the dots, subscripts, and superscripts are misaligned.

Fig. 13. Fractions of the parallel heat transfer through the solid-phase $\left(\dot{q}_{s}^{p} / \dot{q}\right)$ and the fluid-phase $\left(\dot{q}_{f}^{p} / \dot{q}\right)$; also shown is the fraction of the series heat transfer through the solid and fluid phases $\left(\dot{q}_{s f}^{p} / \dot{q}\right)$ vs. porosity: comparisons between the re-examined parallel and the reexamined parallel-series models.

11) On Page 13, first column, second paragraph, correct $\left(\dot{q}_{s}^{p} / \dot{q}\right),\left(\dot{q}_{f}^{p} / \dot{q}\right)$, and $\left(\dot{q}_{s f}^{p} / \dot{q}\right) ;$ the dots, subscripts, and superscripts are misaligned.

Fractions of the parallel heat transfer through the solid-phase $\left(\dot{q}_{s}^{p} / \dot{q}\right)$ and through the fluid-phase $\left(\dot{q}_{f}^{p} / \dot{q}\right)$, as predicted by the re-examined parallel and parallel-series model, are shown in Fig. 13; where $\dot{q}$ is the total heat transfer rate. Also shown in Fig. 13 is a fraction of the series heat transfer through the solid and fluid phases $\left(\dot{q}_{s f}^{p} / \dot{q}\right)$, as predicted by the parallel-series model.

12) On Page 15, Appendix B, Table 2; Correct the equations by adding the overbars; they are missing on some variables; correct the subscripts and superscripts, interference, by adding more space between lines.

Table 2 The classical and re-examined parallel models

\begin{tabular}{|c|c|c|c|c|}
\hline Description & Classical parallel model & Equation & Re-examined parallel model & Equation \\
\hline Cross-sectional areas & $\begin{array}{l}\bar{A}_{s}^{p}=1-P \\
\bar{A}_{f}^{p}=P\end{array}$ & $\begin{array}{l}(6 a) \\
(6 b)\end{array}$ & $\begin{array}{l}\bar{A}_{s}^{p}=(1-P)^{n} \\
\bar{A}_{f}^{p}=1-(1-P)^{n}\end{array}$ & $\begin{array}{l}(21 b) \\
(21 b)\end{array}$ \\
\hline Lengths of heat transfer pathway & $\bar{L}_{s}^{p}=\bar{L}_{f}^{p}=1$ & (4) & $\begin{array}{l}\bar{L}_{s}^{p}=(1-P)^{1-n} \\
\bar{L}_{f}^{p}=P /\left(1-(1-P)^{n}\right)\end{array}$ & $\begin{array}{l}(22 a) \\
(22 b)\end{array}$ \\
\hline Langmuir shape factors & $\begin{array}{l}\bar{S}_{s}^{p}=1-P \\
\bar{S}_{f}^{p}=P\end{array}$ & $\begin{array}{l}(25 \mathrm{a}) \\
(25 \mathrm{~b})\end{array}$ & $\begin{array}{l}\bar{S}_{s}^{p}=(1-P)^{2 n-1} \\
\bar{S}_{f}^{p}=\left(1-(1-P)^{n}\right)^{2} / P\end{array}$ & $\begin{array}{l}(23 a) \\
(23 b)\end{array}$ \\
\hline $\begin{array}{l}\text { Effective thermal conductivity } \\
\text { Fitting parameter }\end{array}$ & $\bar{k}_{e}=\bar{S}_{s}^{p}+\bar{k}_{f} \bar{S}_{f}^{p}$ & (18) & $\begin{array}{l}\bar{k}_{e}=\bar{S}_{s}^{p}+\bar{k}_{f} \bar{S}_{f}^{p} \\
n=1.567\end{array}$ & (18) \\
\hline Coefficient of determination & & & $R^{2}=0.93$ & \\
\hline Root mean square error & & & $R M S E=0.045$ & \\
\hline
\end{tabular}


13) On Page 15, Appendix B, Table 3; Correct the equations by adding the overbars; they are missing on some variables; correct the subscripts and superscripts, interference, by adding more space between lines.

Table 3 The classical and re-examined series models

\begin{tabular}{|c|c|c|c|c|}
\hline Description & Classical series model & Equation & Re-examined series model & Equation \\
\hline Contact area & $\bar{A}^{s}=1$ & (12) & $\bar{A}^{s}=1+a P^{m}(1-P)$ & (32) \\
\hline $\begin{array}{l}\text { Lengths of heat transfer } \\
\text { pathway }\end{array}$ & $\begin{array}{l}\bar{L}_{s}^{s}=1-P \\
\bar{L}_{f}^{s}=P\end{array}$ & $\begin{array}{l}(14 a) \\
(14 b)\end{array}$ & $\begin{array}{l}\bar{L}_{s}^{s}=(1-P) /\left(1+a P^{m}(1-P)\right) \\
\bar{L}_{f}^{s}=P /\left(1+a P^{m}(1-P)\right)\end{array}$ & $\begin{array}{l}(33 a) \\
(33 b)\end{array}$ \\
\hline Langmuir shape factors & $\begin{array}{l}\bar{S}_{s}^{s}=1 /(1-P) \\
\bar{S}_{f}^{s}=1 / P\end{array}$ & $\begin{array}{l}(34 a) \\
(34 b)\end{array}$ & $\begin{array}{l}\bar{S}_{s}^{S}=\left(1+a P^{m}(1-P)\right)^{2} /(1-P) \\
\bar{S}_{f}^{s}=\left(1+a P^{m}(1-P)\right)^{2} / P\end{array}$ & $\begin{array}{l}(34 a) \\
(34 b)\end{array}$ \\
\hline Effective thermal conductivity & $\bar{k}_{e}=\bar{k}_{f} \bar{S}_{f}^{s} \bar{S}_{s}^{s} /\left(\bar{S}_{s}^{s}+\bar{k}_{f} \bar{S}_{f}^{s}\right)$ & $(28)$ & $\bar{k}_{e}=\bar{k}_{f} \bar{S}_{f}^{s} \bar{S}_{s}^{s} /\left(\bar{S}_{s}^{s}+\bar{k}_{f} \bar{S}_{f}^{s}\right)$ & $(28)$ \\
\hline $\begin{array}{l}\text { Fitting parameter } \\
\text { Coefficient of determination } \\
\text { Root mean square error }\end{array}$ & & & $\begin{array}{l}a=109.1 ; m=0.513 \\
R^{2}=0.89 \\
R M S E=0.054\end{array}$ & \\
\hline
\end{tabular}

14) ON Page 15, Appendix B, Table 4; Correct the equations by adding the overbars; they are missing on some variables; correct the subscripts and superscripts, interference, by adding more space between lines.

Table 4 The re-examined parallel-series model

\begin{tabular}{|c|c|c|}
\hline Description & Re-examined parallel-series model & Equation \\
\hline Cross-sectional areas & $\begin{array}{l}\bar{A}_{s}^{p}=(1-P)^{n} \\
\bar{A}_{f}^{p}=1-(1-P)^{n}\end{array}$ & $\begin{array}{l}(38 \mathrm{a}) \\
(38 \mathrm{~b}) \\
(38 \mathrm{c})\end{array}$ \\
\hline Contact area & $\bar{A}^{s}=a P^{m}(1-P)$ & \\
\hline Lengths of heat transfer pathway & $\begin{array}{l}\bar{L}_{s}^{p}=(1-P)^{1-n} \\
\bar{L}_{f}^{p}=P /\left(1-(1-P)^{n}\right) \\
\bar{L}_{S}^{S}=(1-P) /\left(1+a P^{m}(1-P)\right) \\
\bar{L}_{f}^{s}=P /\left(1+a P^{m}(1-P)\right)\end{array}$ & $\begin{array}{l}\text { (39a) } \\
\text { (39b) } \\
\text { (39c) } \\
\text { (39d) }\end{array}$ \\
\hline Langmuir shape factors & $\begin{array}{l}\bar{S}_{s}^{p}=(1-P)^{2 n-1} \\
\bar{S}_{f}^{p}=\left(1-(1-P)^{n}\right)^{2} / P \\
\bar{S}_{s}^{s}=\left(a P^{m}(1-P)\right)^{2} /(1-P) \\
\bar{S}_{f}^{s}=\left(a P^{m}(1-P)\right)^{2} / P\end{array}$ & $\begin{array}{l}(40 \mathrm{a}) \\
(40 \mathrm{~b}) \\
(40 \mathrm{c}) \\
\text { (40d) }\end{array}$ \\
\hline Effective thermal conductivity & $\bar{k}_{e}=\bar{S}_{s}^{p}+\bar{k}_{f} \bar{S}_{f}^{p}+\bar{k}_{f} \bar{S}_{s}^{s} \bar{S}_{f}^{s} /\left(\bar{S}_{s}^{s}+\bar{k}_{f} \bar{S}_{f}^{s}\right)$ & (36) \\
\hline $\begin{array}{l}\text { Fitting parameters } \\
\text { Coefficient of determination } \\
\text { Root Mean Square Error }\end{array}$ & $\begin{array}{l}a=179.7 ; m=2.307 ; n=1.728 \\
R^{2}=0.95 \\
R M S E=0.038\end{array}$ & \\
\hline
\end{tabular}

The original article has been corrected.
Publisher's note Springer Nature remains neutral with regard to jurisdictional claims in published maps and institutional affiliations. 